\title{
Drogman nocturne
}

\section{Olga Duhamel}

In the foreign night of a foreign country, perceptions oscillate between anxiety and sulphurous communion.

Une nuit, alors que l'on avait bu quelques verres et même quelques bouteilles pour obliger nos hôtes, des connaissances du travesti, j'avais perçu avec plus de netteté que nous étions à l'étranger. À mesure que ma tête s'embrouillait, je percevais avec plus d'acuité l'étrangeté des lieux, l'étrangeté de la langue, l'exotisme qui recouvrait chacune des choses sur lesquelles mon regard se posait pour une première fois. Ces gens-là aimaient le fait que nous venions de loin. De toute façon, ils traînaient le plus souvent avec des gens de passage, de même qu'ils avaient des conversations vides. Le lointain restait une espérance vague pour eux. Et l'on continuait à discuter de façon impersonnelle à l'aide de formules approximatives, immergées pourtant dans une sorte de piscine creusée par la chaleur et l'exotisme hypnotique, et remplie de bien-être. Le jardin était noir, sinon une petite lampe à pétrole. Et le travesti faisait avec application la maîtresse de maison.

Un chauffeur de taxi tourne sur les boulevards à la recherche de touristes à escroquer. Les guides de voyage conseillent de ne jamais prendre un taxi dans la rue ici. De même que l'on déconseille aux femmes seules de sortir la nuit. Il n'y a que les putains qui sortent seules dans la nuit confisquée par les brutes. Les autres femmes qui ont à sortir ne le font que sous escorte masculine. On oriente les femmes dans la ville, on se charge de les repousser à l'intérieur des maisons en pensant à leur chatte mystérieusement profonde, à leur corps doux et pâle, maladivement gardé du soleil, maladivement empêché de nudité et qui donne naissance à plusieurs enfants. On guide les femmes dans la ville, à la tombée de la nuit, une épaisse frontière se dessine pour les femmes. Beaucoup d'entre elles sont tout aussi sottes que les brutes. Toutes évitent durant le jour les lieux réservés aux hommes, avec souvent un air discret, parfaitement ridicule. Tout le jour, elles s'affairent à quantité de choses pour les enfants, le mari et la nourriture. Elles gardent un air méfiant dehors, dans la ville hostile la nuit aux femelles. Mais dans le jardin, nous étions à l'abri, dissimulées par la végétation et les hautes clôtures. Nous aussi nous restions assez discrètes avec nos hôtes. Perdues dans cette ville effrayante pour nous qui ne connaissions personne ici, mis à part le travesti. Je ne voulais pas disparaître. Je ne voulais pas être jetée une fois morte aux requins, au large de la ville. Je craignais qu'on égorge Venise devant moi afin de me servir une leçon. Je restais calme, douce. Les rues ici la nuit étaient aussi peu sûres que les ruelles du Moyen Âge et les femmes ne s'y aventuraient pas sous peine d'être suppliciées ou simplement corrigées, si on avait de la chance, dans une cage 
d'escalier ou encore, publiquement. Je restais calme en surface, tandis que toute l'étrangeté des lieux me rendait paranoïaque. Je savais que je n'étais pas chez les barbares, mais je ne parvenais pas à empêcher cet enfoncement psychologique dans les villes barbares. Et durant un certain temps, tout devenait vraiment suspect de ces inconnus qui parlaient avec de grands rires et une langue mystérieuse, mais surtout, l'extérieur du jardin, ce quartier sinistre de la ville, m'effrayait et la menace perpétuelle qui s'était tant estompée pour les femmes en Occident bien qu'elle n'ait pas disparue, revenait plus intensément dans ma tête à la façon d'un délire. La délirante menace qui pèse sur les femmes la nuit s'étirait dans ma tête, mais je restais calme. Et Venise à présent essayait de me changer les idées. Elle m'avait resservie à boire et me demandait de traduire une bêtise ou une autre pour nos hôtes, qui nous traitaient très bien en vérité. On faisait honneur aux gâteaux, aux alcools. On était de gentilles voyageuses et je m'appliquais dans la mesure de mes capacités à faire l'interprète. Le travesti souriait de plus en plus à Venise qui lui rendait son sourire. L'alcool nous hissait à une hauteur supérieure, celle de la compréhension aiguë de toute chose qui risque cependant à tout moment de basculer dans son envers.

La mer est à peine à quelques kilomètres d'ici. La ville a grugé toute la côte. Mais il y avait le bois où le travesti voulait nous amener de nouveau. Dans le bois, j'étais frappée par cette manière venue d'un autre temps, un temps aujourd'hui historique, de mettre en scène la nature. Les grandes allées arborées et les étangs appartenaient à une esthétique ancienne que l'on pouvait voir encore dans les vieilles gravures et dans les vieux quartiers d'Europe: l'éternelle nature sauvage du $18^{\mathrm{e}}$ siècle. Habitée ici par des créatures de la nuit, homos tout autant que prostituées, qui se retrouvaient pour faire du commerce et traîner longuement en attendant les affaires. La nuit nous protège à présent. Ici, la langue devient plus familière. Je suis restée avec nos hôtes et des inconnus, tandis que Venise, accompagnée du travesti, s'est laissée avaler par l'ombre jusqu'à ce que je la retrouve une heure ou deux plus tard, enfoncée dans la partie la plus sombre et la plus peuplée du bois, heureuse, me semblait-il, mais sans empressement, que l'on se retrouve. Ici, cette nuit, la fange se fait drogman de la liberté. 